\title{
Experimental Study of the Effect of Polyacrylate Polymer (C16-C22) on Wax Deposition
}

\author{
Muhammad Ali Theyab and Pedro Diaz
}

\begin{abstract}
Wax can precipitate as a solid phase on the pipe wall during hydrocarbon production when its temperature (inlet coolant temperature) drops below the Wax Appearance Temperature (WAT) causing an artificial blockage leading to a reduction or interruption in the production. An experimental flow loop system was built in the lab to study the variation of wax deposition thickness under a single phase transport. The effect of the inhibitor W802 (polyacrylate polymer (C16-C22)) on the crude oil viscosity and WAT was studied at different concentrations using a Bohlin Gemini II rheometer. The results show the greatest reduction in oil viscosity was achieved when using $1000 \mathrm{ppm}$ of $\mathbf{W 8 0 2}$ which means a greater reduction in the wax deposition using this inhibitor concentration. A series of experiments were carried out to study wax deposition and measure the wax thickness using four different techniques including pigging, pressure drop, heat transfer, liquid displacement-level detection (LD-LD). The effect of factors on wax formation such as inlet coolant temperature, pressure drop, flow rates, time, and inhibitor has been examined. The results show the wax inhibition percentage (WI\%) using inhibitor W802 (polyacrylate polymer (C16-C22)) at flow rate $4.8 \mathrm{~L} / \mathrm{min}$ was higher at higher inlet coolant temperatures from $40 \%$ at 14 ${ }^{\circ} \mathrm{C}$, to $57 \%$ at $24{ }^{\circ} \mathrm{C}$ and $100 \%$ at $33{ }^{\circ} \mathrm{C}$. This percentage of inhibition will increased rapidly by increasing the inlet coolant temperature.
\end{abstract}

Index Terms-Waxy crude oil, inhibitor, WAT, Viscosity.

\section{INTRODUCTION}

Wax deposition is one of the main flow assurance problems in the oil industry. Wax deposition can result in the restriction of crude oil flow in the pipeline, creating pressure abnormalities and causing an artificial blockage leading to a reduction or interruption in the production. However, in an extreme case, this can cause a pipeline or production facility to be abandoned [1]. Wax can precipitate, arising when paraffin components in crude oil precipitate and deposit on the cold pipeline wall when the inner wall temperature (inlet coolant temperature) drops below the wax appearance temperature [2]-[4]. Wax appearance temperature (WAT) is the temperature at which paraffin wax start to precipitate [5].

The main factor that affects the wax deposition process is the low temperature, which means that subsea pipelines are especially vulnerable. Therefore, wax deposition prevention becomes very important in deep- water oil production.

Wax deposition in crude oil production systems can be reduced or prevented by one or combination of chemical,

Manuscript received March 11, 2016; revised August 20, 2016.

Muhammad Ali Theyab is with London South Bank University, 103 Borough Rd, London SE1 0AA, USA (e-mail: theyabm@1sbu.ac.uk).

Pedro Diaz is with the School of Engineering, London South Bank University, UK (e-mail: diazp2@1sbu.ac.uk). mechanical, and thermal remediation methods. However, with the advent of extremely deep production, offshore drilling and ocean floor completions, the use mechanical and thermal remediation methods becomes prohibitive economically, as a result, use of chemical additives as wax deposition inhibitors is becoming more prevalent [6]. Selected chemical inhibitor was tested in the current work to study its effect on wax deposition.

In order to study the influence of factors that affect the formation of wax deposits such as inlet coolant temperature, flow rate $(2.7$ and $4.8 \mathrm{~L} / \mathrm{min})$, pressure drop, deposit time, and $1000 \mathrm{ppm}$ of the inhibitor W802 polyacrylate polymer (C16-C22), wax deposition experiments were carried out. Four different methods were followed to measure the wax thickness deposited in the rig pipe, including pigging, pressure drop, heat transfer and liquid displacement-level detection (LD-LD).

The results show a good inhibition percentage at flow rate $4.8 \mathrm{~L} / \mathrm{min}$ and different coolant temperature reach to $100 \%$ at inlet coolant temperature $33^{\circ} \mathrm{C}$. This percentage of inhibition increases rapidly at higher inlet coolant temperatures.

\section{EXPERIMENTAL METHODOLOGY}

\section{A. Characterization of Crude Oil}

The crude oil that has been used in this study is one of the oil fields reservoirs with waxing problems of Arunachal Pradesh state in the extreme north eastern part of India. The crude oil was characterized in the lab using standard analytical methods as shown in Table I.

TABLE I: CRUDE OIL CHARACTERISTICS

\begin{tabular}{|c|c|c|c|}
\hline Characteristics & Unit & Value & Experimental Method \\
\hline Density & $\mathrm{kg} / \mathrm{m}^{3}\left(15^{\circ} \mathrm{C}\right)$ & 850 & mass/volume \\
\hline Sp. Gravity & $60 / 60^{\circ} \mathrm{F}$ & 0.85 & Calculated \\
\hline API Gravity & $60^{\circ} \mathrm{F}$ & 34.97 & API Method \\
\hline $\begin{array}{l}\text { WAT at shear } \\
\text { rate } 101 / \mathrm{s}\end{array}$ & ${ }^{\circ} \mathrm{C}$ & 39 & Rheometer \\
\hline $\begin{array}{l}\text { WAT at shear } \\
\text { rate } 1201 / \mathrm{s}\end{array}$ & ${ }^{\circ} \mathrm{C}$ & 30 & Rheometer \\
\hline Pour Point & ${ }^{\circ} \mathrm{C}$ & 27.6 & Rheometer \\
\hline Wax Content & wt $\%$ & 20.15 & ASTM D721 \\
\hline Saturates & wt $\%$ & 74.91 & SARA \\
\hline Aromatics & wt $\%$ & 20.44 & SARA \\
\hline Resins & wt $\%$ & 4.26 & SARA \\
\hline Asphaltene & wt $\%$ & 0.39 & SARA \\
\hline
\end{tabular}

\section{B. Wax Deposition Methodology}

The investigation of the parameters affecting the wax deposition included:

- Study the effect of a polyacrylate based polymer 
(C16-C22) as inhibitor of wax deposition by evaluating its effect on the crude oil viscosity.

- Study the influence inlet coolant temperature, flow rate, and experiment running time on the wax deposition process, by using a laboratory rig.

The performance of the wax inhibitor W802 (polyacrylate polymer (C16-C22)) was evaluated at different concentrations $(250,500,750,1000$ and $2000 \mathrm{ppm})$ by determining its effect on the crude oil viscosity and wax appearance temperature using a Bohlin Gemini II rheometer. A minimum viscosity corresponding to the higher reduction of wax deposition was achieved when using 1000ppm of the inhibitor.

\section{Experimental Rig Design}

This rig was built in the lab to study the variation of wax deposition thickness under different conditions. This system allowed the investigate the effect of some of the factors that control the wax deposition process, such as inlet coolant temperature, flow rate, and use of inhibitors. The test flow loop built consists as shown in Fig. 1 of:

- A crude oil pipe made of a $150 \mathrm{~cm}$ long copper tubing with an inside diameter of $1.35 \mathrm{~cm}$.

- The crude oil pipe is jacketed with a wider diameter copper pipe. Cold water is pumped from the chiller through the annulus of the concentric pipes to maintain pipe wall temperature lower than wax appearance temperature.

- A pump is used to recirculate crude oil through the inner pipe a several flow rates from a three-neck flask. One of these necks allows returning the crude oil to the flask after being pumped through the pipe. The second neck allows feeding the crude oil to the pump, and the third neck is for a condenser. This flask is fixed in a controlled heating bath.

- A condenser used to condense the light components that were evaporated from heating crude oil.

- Two thermocouples to measure temperatures of crude oil at the inlet and outlet of the pipe.

- Two thermocouples used to measure the recycling cooling water and the inner pipe wall surface temperatures.

- Two pressure gauges are used to determine the pressure drop along the test section of the pipe.

- The temperature Pico meter connected to the computer to read the temperatures of thermocouples.

The copper pipe used in the experiments facilitates cooling down the transported crude oil due to its high thermal conductivity, this might lead to more wax precipitation in a shorter time compared with other metals. This reduces the experiment time as the formation of wax is a faster process in the designed rig.

In an experiment run the waxy crude oil was pumped through the inner pipe at a relatively higher temperature than the wall coolant temperature, to create the appropriate environment for the deposition inside the test section. The pressure drop along the length of the pipe was then measured. Experiments for different flow rates $(2.7$ and $4.8 \mathrm{~L} / \mathrm{min})$ were carried out, with and without inhibitors at different experiment running or aging time $(2,4$, and $6 \mathrm{~h})$, and different coolant temperature $\left(14,24,33\right.$, and $\left.40^{\circ} \mathrm{C}\right)$.

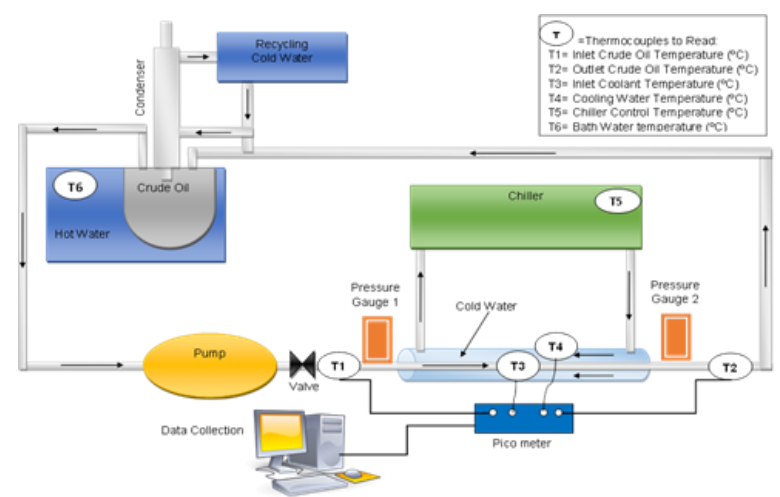

Fig. 1. Schematic of wax deposition test flow loop in this study.

\section{Methods to Measure the Wax Thickness}

Four different methods have been used in this work to measure wax deposit thickness inside the pipe. These methods are called pigging method, pressure drop method, heat transfer method and liquid displacement-level detection technique (LD-LD).

The pigging method is based on the concept of passing spheres through the test section and measuring the wax volume removed [7]. In this study a plastic cone has been used instead of the sphere for the wax pigging.

The pressure drop method is based on the concept that wax deposition in a pipe section reduces the hydraulic diameter of the flowing fluid inside the pipe, resulting in an increase in frictional pressure drop over the pipe section [7], [2]. The wax thickness present in the pipe wall can be calculated accurately from the following equation presented by Chen $e t$ al., (1997) [8]:

$$
\left(d_{i}-2 \delta_{w}\right)^{5-n}=\frac{2 c \rho L}{\Delta p_{f}}\left(\frac{\mu}{\rho}\right){ }^{n}\left(\frac{4 Q}{\pi}\right)^{2-n}
$$

where $\Delta p_{f}$ is the pressure drop, $L$ is the length of pipe section, $d$ is the hydraulic diameter or effective inside diameter, $Q$ is the volumetric flow rate, $\rho$ is the fluid density, where $\mu$ is the apparent viscosity of the crude oil. $c=16, n$ $=1$ for laminar flow and $c=0.046, n=0.2$ for turbulent flow. Laminar flow exists when $\mathrm{NRe}<2000$, [7]. This method is an on-line technique that does not require depressurization and restarting in order to obtain wax measurements [7].

After the wax deposit layer is formed on the pipe wall, a convective heat transfer occurs between the flowing fluids and the deposited wax layer. A thermal resistance term due to heat conduction through the wax layer is added to the total resistance to the heat transfer from the flowing fluid to the environment. The wax thickness can be measured from the heat transfer equation.

$$
\frac{T_{f}-T_{o}}{q_{o}}=\frac{1}{h_{w}} \frac{r_{o}}{r_{i}-\delta_{w}}+\frac{r_{o}}{k_{w}} \ln \frac{r_{i}}{r_{i}-\delta_{w}}+\frac{r_{o}}{k_{p}} \ln \frac{r_{o}}{r_{i}}
$$

where $T_{f}$ is the bulk fluid temperature in the pipe, $T_{o}$ is the outside pipe wall temperature, $q_{o}$ is the heat flux through the outside pipe wall, $r_{o}$ and $r_{i}$ are the outside and inside diameters of the pipe, respectively, $h_{w}$ is the film heat transfer coefficient from the flowing fluid to the wax layer, $k_{p}$ and $k_{w}$ are the thermal conductivities of the pipe wall and deposited 
wax, respectively, and $\delta_{w}$ is the thickness of wax layer. The method liquid displacement-level detection method (LD-LD) is based on replacing the test tube by liquid (water in this study) and measure the volume of the tube before and after carrying out the experiment, the difference between the two volumes represent the volume of wax inside the pipe.

\section{RESUlTS AND ANALYSIS}

\section{A. Estimating Wax Thickness Using Different Methods}

Tables II and III show a comparison between the thickness estimate using four methods at different flow rates. The results show a good match between the wax volumes measured using the pigging and LD-LD methods. The pressure drop and heat transfer methods are show a similarity in the results at high pressure drop and slightly different at lower pressure drop at the same flow rate.

\section{B. Effect of Inlet Coolant Temperature}

Fig. 2 shows how the inlet coolant temperature affects the wax deposition inside the pipe. During run the experiments, it was noted that the wax deposit thickness increased at lower inlet coolant temperature even when was the crude oil temperature above wax appearance temperature, that means wax deposition depend on the inlet coolant temperature more than it depend on the crude oil temperature. Wax thickness increased to $1.83 \mathrm{~mm}$ at the end of the experiment when the inlet coolant temperature was equal to $14^{\circ} \mathrm{C}$. The wax thickness decreased when the inlet coolant temperature increased $\left(24,33,40^{\circ} \mathrm{C}\right)$ respectively and stopped to precipitate at $40^{\circ} \mathrm{C}$ as shown in Fig. 2, where this temperature is above wax appearance temperature.

TABLE II: WAX THICKNESS AT FLOW RATE 4.8 L/MIN. USING DIFFERENT

\begin{tabular}{ccccc}
\multicolumn{5}{c}{ TECHNIQUES } \\
$\begin{array}{c}\text { Coolant } \\
\text { Temp. } \\
\left({ }^{\circ} \mathrm{C}\right)\end{array}$ & $\begin{array}{c}\text { Wax } \\
\text { Thickness } \\
\text { mm(Pigging } \\
\text { Method) }\end{array}$ & $\begin{array}{c}\text { Wax } \\
\text { Thickness } \\
\text { mm(Pressure } \\
\text { Drop) }\end{array}$ & $\begin{array}{c}\text { Wax } \\
\text { Thickness } \\
\text { mm(Heat } \\
\text { Transfer) }\end{array}$ & $\begin{array}{c}\text { Wax } \\
\text { Thickness mm } \\
(\text { LD-LD) }\end{array}$ \\
\hline 14 & 1.5 & 1.72 & 1.72 & 1.52 \\
24 & 1.36 & 1.45 & 1.27 & 1.36 \\
33 & 0.63 & 0.79 & 0.65 & 0.67 \\
40 & 0 & 0.054 & 0 & 0 \\
\hline
\end{tabular}

TABLE III: MEASURING WAX THICKNESS USING DIFFERENT TECHNIQUES

\begin{tabular}{ccccc}
\multicolumn{5}{c}{ AT Flow RATE 2.7 L/MiN } \\
$\begin{array}{c}\text { Coolant } \\
\text { Temp. } \\
\left({ }^{\circ} \mathrm{C}\right)\end{array}$ & $\begin{array}{c}\text { Wax } \\
\text { Thickness } \\
\text { mm(Pigging } \\
\text { Method) }\end{array}$ & $\begin{array}{c}\text { Wax } \\
\text { Thickness } \\
\text { mm(Pressure }\end{array}$ & $\begin{array}{c}\text { Wax } \\
\text { Thickness } \\
\text { mm(Heat }\end{array}$ & $\begin{array}{c}\text { Wax } \\
\text { Thickness } \\
\text { mm(LD-LD }\end{array}$ \\
\hline 14 & 1.82 & 1.83 & Transfer) & ) \\
24 & 1.5 & 1.61 & 1.83 & 1.84 \\
33 & 0.7 & 0.69 & 0.71 & 1.5 \\
40 & 0 & 0.04 & 0.06 & 0.73 \\
\hline
\end{tabular}

\section{Effect of Inlet Coolant Temperature}

Fig. 2 shows how the inlet coolant temperature affects the wax deposition inside the pipe. During the experiments runs, it was noted that the deposit thickness increased at lower inlet coolant temperature, even when the crude oil temperature was above the wax appearance temperature, that means wax deposition depend on the inlet coolant temperature. Wax thickness increased to $1.8 \mathrm{~mm}$ at the end of the experiment when the inlet coolant temperature was equal to $14^{\circ} \mathrm{C}$. The wax thickness decreased at higher inlet coolant temperature $\left(24,33^{\circ} \mathrm{C}\right)$, and no wax deposit occurred at $40^{\circ} \mathrm{C}$ as shown in Fig. 2, this was expected as this temperature is above wax appearance temperature.

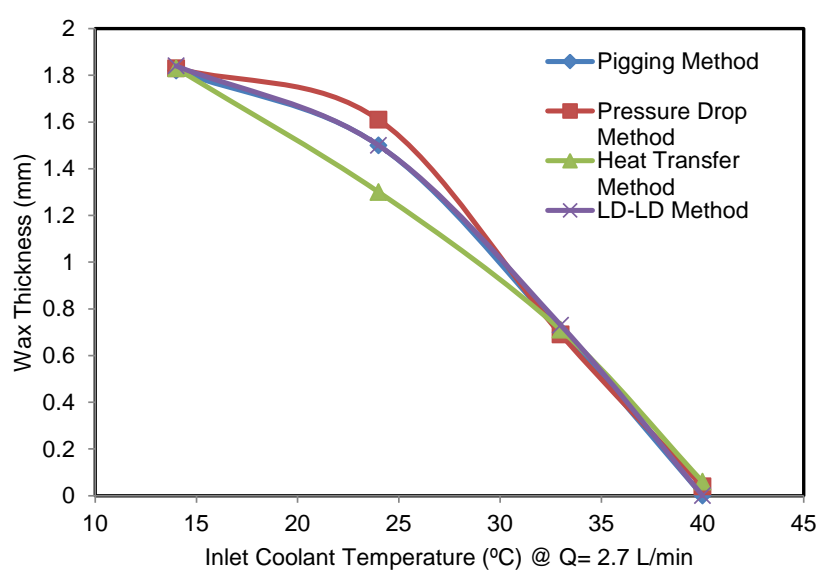

(a)

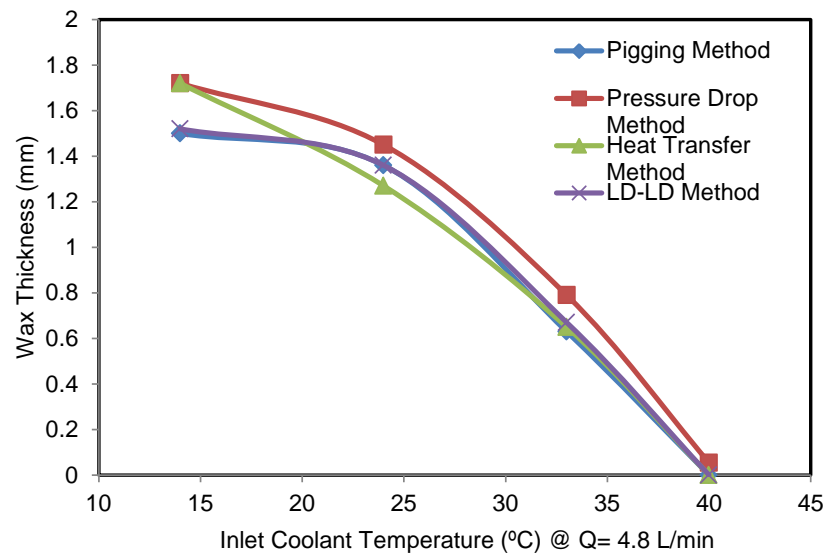

(b)

Fig. 2. The effect of inlet coolant temperature on wax thickness at different flow rates (a) $2.7 \mathrm{~L} / \mathrm{min}$ (b) $4.8 \mathrm{~L} / \mathrm{min}$, and different techniques.

\section{Effect of Flow Rate on Wax Deposition}

From Fig. 3, it can be observed that at a given temperature the wax deposit is thicker at low flow rate $(2.7 \mathrm{~L} / \mathrm{min}$.) while the deposit was thinner at higher oil flow rate $(4.8 \mathrm{~L} / \mathrm{min}$. $)$.

As the flow rate increases, the strength of adverse forces opposing the wax deposition increase as well. These adverse forces work as a kind of viscous force which tends to drag or slough the wax deposits from the pipe wall. When this viscous drag exceeds the resistance to shear in the deposits, the wax then sloughs and is lodged back into the liquid [8].

The resistance to shear in the deposits is given by the cohesive and adhesive forces between the paraffin wax molecules and the deposition surface; they are are overcome by the rate of shear [9]. As a result, the wax deposition is reduced by increasing the flow rate.

The addition of the inhibitor W802 to the crude oil results in the reduction of the wax thickness from $1.8 \mathrm{~mm}$ to $1.2 \mathrm{~mm}$ at $14{ }^{\circ} \mathrm{C}$ as shown in Fig. 3.

The inhibitor affects the growth of the wax crystals, leading to small aggregates of wax; this is evidenced as a reduction of the oil viscosity, and the thickness of the wax deposit (Fig. 3). 


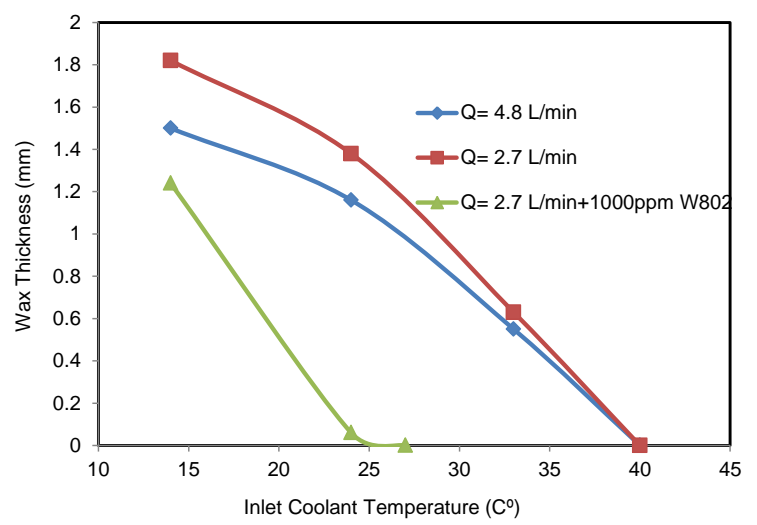

Fig. 3. The effect of flow rate on wax thickness.

\section{E. Effect of Time on Wax Thickness}

It was observed in this study that the wax deposit increased regularly by the first two hours of running the experiments at different flow rates due, as mentioned by Abdel-Waly (1999) [10]. In initial stages of the experiment there is a steep increase in wax deposition as more paraffin molecules are deposited from fresh crude oil transported through the pipe from the flask.

The wax deposition increases with the crude oil recirculation time, irrespective of the operating conditions, until it reaches an asymptotic value at steady state conditions [11]. Studies have shown that a thermal pseudo-steady state is attained in less than 30 minutes during deposition from wax solvent mixtures under laminar and turbulent conditions [12], [13]. Laboratory studies have also shown a negligible increase in the mass of the deposit after 4 hours [11]. This is observed in Fig. 4.

After two hours of the experiment, the heat transfer between the crude oil and the pipe wall is reduced due to the heat insulation created by the wax deposit layer in the pipe wall. This leads to a relative increase in crude oil temperature and a reduction in the deposition process. Therefore after two hours of carrying out the experiment the deposit thickness along the pipe will be in the shape of a curve due to an increase in wax solubility as shown in Fig. 4.

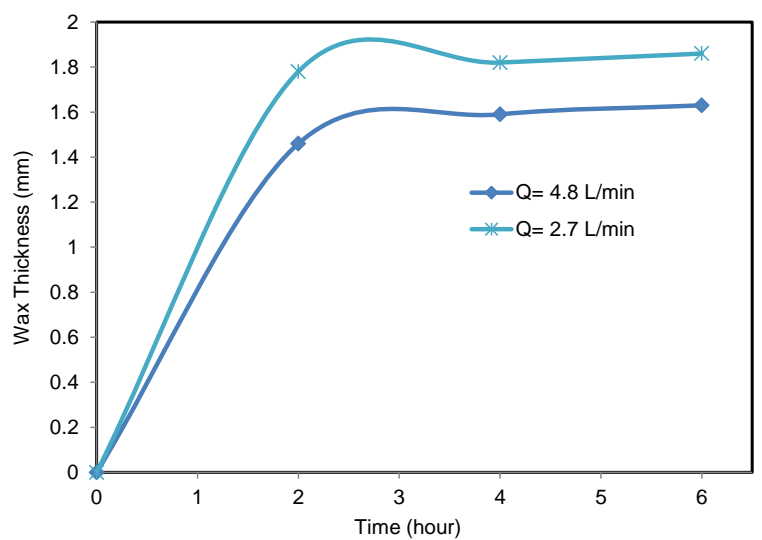

Fig. 4. The effect of time on wax deposition thickness at different flow rates.

\section{F. Effect of Poly Acrylate Polymer on Wax Deposition}

The study of the effect of the inhibitor W802 (polyacrylate polymer (C16-C22)) on the viscosity of the crude oil at different concentration (250, 500, 750, 1000 and $2000 \mathrm{ppm})$ showed that the greatest reduction in viscosity at $1000 \mathrm{ppm}$.
Any further increase of inhibitor concentration (e.g. 2000ppm) had only a small additional effect on the viscosity.

This inhibitor W802 at a concentration 1000ppm has been examined with the crude oil at different flow rates $(2.7$ and $4.8 \mathrm{~L} / \mathrm{min}$ ) using the flow rig.

Fig. 5 shows that the inhibitor reduced the wax thickness at flow rate $2.7 \mathrm{~L} / \mathrm{min}$ and inlet coolant temperature $14{ }^{\circ} \mathrm{C}$ from $1.9 \mathrm{~mm}$ to $1.4 \mathrm{~mm}$, this consider a great reduction at this low temperature. Also, it reduced the wax thickness from $1.6 \mathrm{~mm}$ to $1.3 \mathrm{~mm}$ at flow rate $4.8 \mathrm{~L} / \mathrm{min}$ and inlet coolant temperature $14{ }^{\circ} \mathrm{C}$.

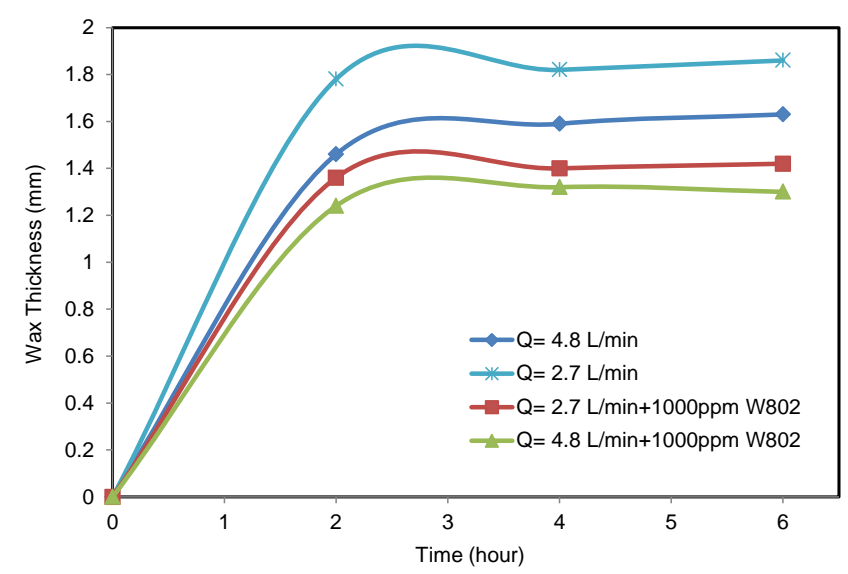

Fig. 5. The effect of inhibitor W802 on wax thickness at 2.7 and $4.8 \mathrm{~L} / \mathrm{min}$, and inlet coolant temperature $14{ }^{\circ} \mathrm{C}$.

Proposed mechanisms of waxing inhibition involve the possibility of wax inhibitor polymers, containing similar structure to the wax structure, are incorporated into the wax crystal growth. Sometimes the structural part of the polymer covers the wax site, thereby preventing further wax crystal growth and promoting the formation of smaller wax aggregates [14], [6].

The effect of the W802 inhibitor (polyacrylate polymer (C16-C22) on wax structure have been examined using the Scanning Electron Microscopy (SEM) as shown in Fig. 6, where it can be seen clearly how the inhibitor effect and changed the wax structure.

The effects of the inhibitor on the thickness of the wax deposit are clearly observed inside the pipe as shown in Fig. 7 (a) without inhibitor and (b) with inhibitor.

\section{G. Evaluation of Wax Inhibition}

Wax Inhibition WI (\%) can be defined as the ratio between the waxing reduction using inhibitor, and the wax deposited without inhibitor (blank oil) at a specific temperature [6].

$$
W I(\%)=100 \frac{W_{b}-W_{w i}}{W_{b}}
$$

$W_{b}=$ Wax deposit by volume of the blank oil (ml).

$W_{w i}=$ Wax deposit by volume during the same period of time treated oil $(\mathrm{ml})$.

Fig. 8 shows that the wax inhibition percentage at flow rate $4.8 \mathrm{~L} / \mathrm{min}$. increased at different inlet coolant temperatures from $40 \%$ at $14{ }^{\circ} \mathrm{C}$, to $57 \%$ at $24{ }^{\circ} \mathrm{C}$ and $100 \%$ at $33{ }^{\circ} \mathrm{C}$. 


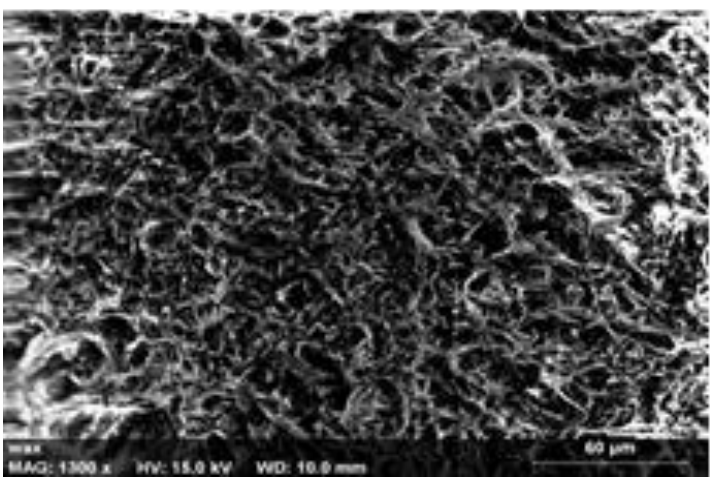

(a)

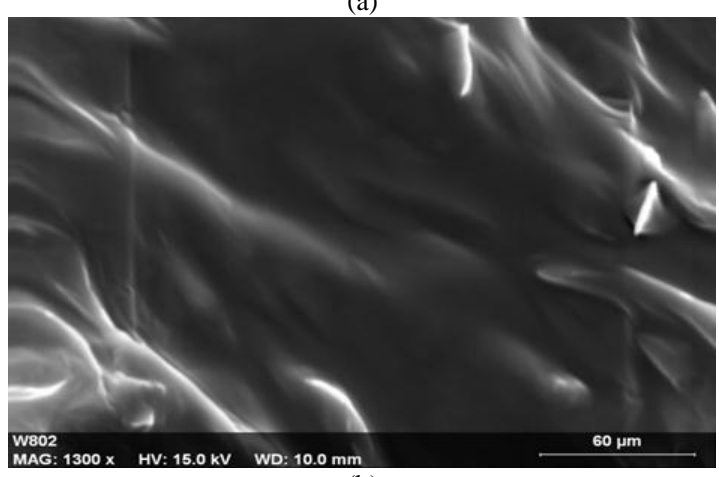

(b)

Fig. 6. The structure of wax before (a) and after (b) adding the inhibitor W802 using SEM.

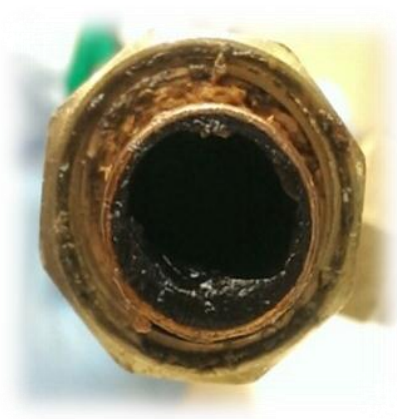

(a)

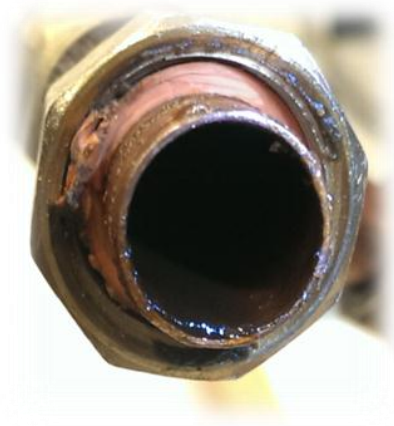

(b)
Fig. 7. The effect of W802 on wax deposition inside the pipe (a) without inhibitor and (b) with inhibitor.

Wax Inhibition

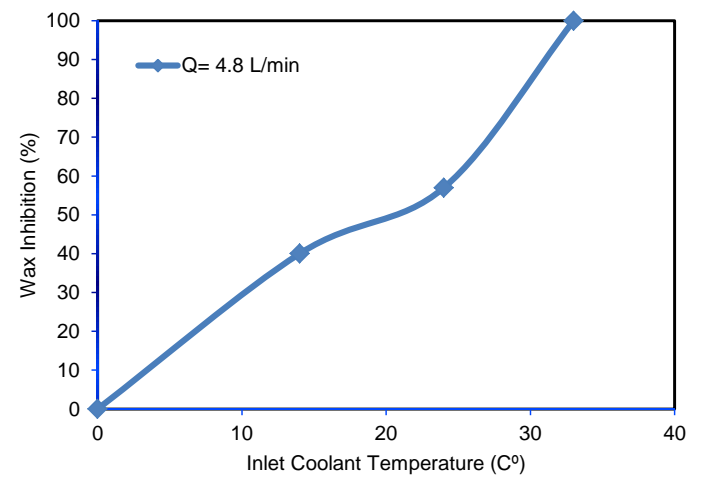

Fig. 8. Wax inhibition $\%$ of the inhibitor W802 at different inlet coolant temperature.

\section{CONCLUSIONS}

The current work studied some aspects of wax deposition which is one of the main flow assurance problems in the oil industry. An apparatus was built to study the effects of some factors on wax formation such as inlet coolant temperature, pressure drop, flow rates, time and inhibitor. Four different methods have been used to estimate the wax thickness in the test section including pigging, pressure drop, heat transfer and liquid displacement-level detection methods.

The wax deposition increases with decreasing the inlet coolant temperature, and decreases and stops above WAT. On the other hand, an increase in flow rate results in a reduction of wax deposition due to increasing the shear stress that overcome cohesive and adhesion forces among the wax molecules and the deposition surface. It was observed in all experiments that at the first two hours of carrying out the experiment the wax deposition rate increased linearly with time before reaching a plateau.

In this study, a chemical additive based on polymers (polyacrylate polymer (C16-C22)) was used to study its effect on wax appearance temperature and the viscosity of the crude oil. The analysis of results show that $1000 \mathrm{ppm}$ was the optimum concentration to be examined with the crude oil at different flow rates $(2.7$ and $4.8 \mathrm{~L} / \mathrm{min})$ using the flow rig.

The results show that the wax inhibition percent using the polyacrylate polymer increased at different inlet coolant temperatures from $40 \%$ at $14{ }^{\circ} \mathrm{C}$, to $57 \%$ at $24{ }^{\circ} \mathrm{C}$ and $100 \%$ at $33{ }^{\circ} \mathrm{C}$.

The inhibitor has been used in the current work is based on polymers which are normally used as pour point depressant. The reduction in the pour point and the crude oil viscosity had been making the transportation of the crude oil easier [15], [6]. This inhibitor was reducing the wax deposition process by interfering with wax crystallization and growth process. However, this interfering mechanism has not yet been fully understood [14].

\section{ACKNOWLEDGEMENTS}

The authors would like to thank the Ministry of Higher Education and Scientific Research/Iraq for the financial support. We would like to thank Miss Heather Blackwood from Roemex Limited Company for help.

\section{REFERENCES}

[1] A. Singh, H. Lee, P. Singh, and C. Sarica, "Flow assurance: validation of wax deposition models using field data from a subsea pipeline," in Proc. Offshore Technology Conference, 2011, pp. 1-19.

[2] Z. Huang, S. Zheng, and H. S. Fogler, Wax Deposition: Experimental Characterizations, Theoretical Modeling, and Field Practices. 1 st ed. Boca Raton, London, New York: Taylor \& Francis Group, 2015.

[3] O. A. Adeyanju and L. O. Oyekunle, "Experimental study of wax deposition in a single phase sub-cooled oil pipelines," presented at 2013 NAICE, 2013

[4] H. S. Lee, "Computational and rheological study of wax deposition and gelation in subsea pipelines," PhD Dissertation, University of Michigan, 2008.

[5] A. Tordal. (2006). Pigging of Pipelines with High Wax Content. [Online] Available: http://www.ppsaonline.com/papers/2006-Aberdeen-1-Tordal.pdf

[6] O. A. Adeyanju and L. O. Oyekunle, "Influence of long chain acrylate ester polymers as wax inhibitors in crude oil pipelines," in Proc. SPE Nigeria Annual International Conference and Exhibition, 2014, pp. $1-13$.

[7] X. T. Chen, B. M. Volk, Bwith Stuck Pig, and J. P. Rill, "Techniques for measuring wax thickness during single and multiphase flow," in Proc. SPE Annual Technical Conference and Exhibition, 1997, pp. 249-256.

[8] T. Zhu, J. A. Walker, and J. Liang, "Evaluation of wax deposition and its control during production of alaska north slope oils," Research Report. Petroleum development laboratory, Institute of Northern Engineering, University of Alaska Fairbanks, 2008. 
[9] T. R. Bott and J. S. Gudmunsson, "Deposition of paraffin wax from kerosene in cooled heat exchanger tubes," Can. J. Chem. Eng., vol. 55, pp. 381-385, 1977.

[10] A. A. Abdel-Waly, "The factors affecting paraffin deposition in oil wells," Journal of Engineering and Applied Science, vol. 46, no. 381, 1999.

[11] A. S. Kasumu, "An investigation of solids deposition from two-phase wax-solvent-water mixtures," PhD Dissertation, Galgary University, 2014.

[12] A. S. Kasumu and A. K. Mehrotra, "Solids deposition from two-phase wax-solvent-water "waxy" mixtures under turbulent flow," Energy \& Fuels, vol. 27, pp. 1914-1925, 2013.

[13] R. Tiwary and A. K. Mehrotra, "Deposition from wax-solvent mixtures under turbulent flow: Effects of shear rate and time on deposit properties," Energy Fuels, vol. 23, pp. 1299-310, 2009.

[14] D. W Jennings and M. E. Newberry, "Paraffin inhibitor applications in deepwater offshore development," in Proc. the International Petroleum Technology Conference, 2008, pp. 1-14.

[15] K. S. Pedersen and H. P. Ronningsen, "Influence of wax inhibitors on wax appearance temperature, pour point, and viscosity of waxy crude oils," Energy and Fuels, vol. 17, no. 2, pp. 321-328, 2003.

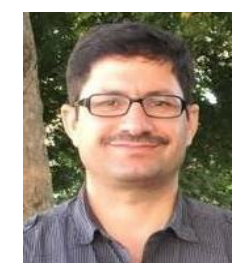

Muhammad Ali Theyab has completed his BSc degree in chemical engineering from Tikrit University, Iraq. He received his $\mathrm{MSc}$ degree in petroleum engineering from London South Bank University and currently he is a $\mathrm{PhD}$ student at the same university. He is employed at the Ministry of Higher Education and Scientific Research, Iraq.

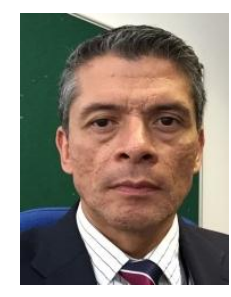

Pedro Diaz is an Associate Professor at the School of Engineering at London South Bank University. And currently, he is the head of the Chemical and Petroleum Engineering Division. 
